\title{
The Bruce Highway Action Plan Program Evaluation
}

\author{
Wayne Mark Davies \\ Department of Transport and Main Roads, Queensland Government, Queensland 4510, Australia
}

\begin{abstract}
The BHAP (Bruce Highway Action Plan) Program Evaluation was a momentous task conducted in most part by the TMR (Transport and Main Roads) CBA (cost benefit analysis) team. The evaluation included 189 overtaking lanes, $404 \mathrm{~km}$ of road widening and shoulder sealing in various places between Brisbane and Cairns, 56 capacity focused projects and 16 flood immunity focused projects. The total projected capital costs of all projects proposed as part of the BHAP amounted to over 16 billion dollars. The program evaluation conducted, due to the short timeframes, lack of available data and strategic nature of the plan, has been "coined" a strategic evaluation. This paper focuses on the methodology applied to the projects proposed in the BHAP. A TMR designed project/program evaluation model (CARP (Concise Analysis of Road Programs) V1.0) was used to evaluate the majority of the proposed BHAP projects. The model produces streams of discounted benefits and costs of the projects and program using limited and incomplete data. The large scale of work and the close proximity of projects allowed for an integrated approach to the analysis, which considered the impact projects have on each other. The result of the program, if all evaluated projects are included, is a BCR (benefit cost ratio) of approximately 0.71 at a discount rate of $7 \%$. If the less viable projects are removed from the program, the program can obtain a benefit cost ratio of greater than 1 with a sufficiently large number of projects remaining.
\end{abstract}

Key words: Program evaluation, cost benefit analysis, Bruce Highway.

\section{Introduction}

The BHAP (Bruce Highway Action Plan) is an engineering based needs assessment that aims over a 10-year period to address capacity, flooding and safety problems along the entire $1,677 \mathrm{~km}$ length of the Bruce Highway from Brisbane to Cairns ${ }^{1}$ [1]. The BHAP proposes over 16 billion dollars worth of improvements to the Bruce Highway over the next 10 years [1]. The projects proposed as part of the BHAP include road widening and shoulder seals, overtaking lanes, bypasses and ring roads, lane duplications, raised bridges and approaches, road realignments, intersection upgrades and minor safety treatments [2]. The poor safety record, frequent flooding and high traffic growth rates are the major impetuses for the BHAP [1].

The TMR (Transport and Main Roads) CBA (cost

Corresponding author: Wayne Mark Davies, M.Sc., senior economist, research fields: transport economics, welfare economics and economic modelling. E-mail: wmd03@yahoo.com.

${ }^{1}$ Appendix C contains a map of the Bruce Highway, which includes the locations of all the BHAP projects. benefit analysis) team was given the task to evaluate and provide economic advice regarding the initial viability and prioritisation of the initial projects to be proposed as part of the BHAP. The BHAP program evaluation consists of projects to be funded under the NBP1 (Nation Building Program 1), NB2 (Nation Building Program 2) and $\mathrm{BHAP}^{2}$. As part of the BHAP, all proposed projects require CBAs. Projects to be funded under NBP1 had already undergone CBAs and these projects, due to the application of different methodologies, have not been combined with the NB2 and BHAP projects. The focus of this paper is the evaluation of projects to be funded as part of NB2 and BHAP.

The BHAP program evaluation was intended as a strategic quantitative evaluation of all projects proposed to be constructed along the Bruce Highway in both the short run and long run. There was an intended timeframe of approximately 3 months from July 2012 to early October 2012 to complete the

${ }^{2} \mathrm{BHAP}$ is referred to as both the funding body as well as the strategic action plan that encapsulates the NBP1, NB2 and BHAP funded projects. 
evaluation of the projects. Given that many of the projects were in the early planning stages, complete information about the scope or data was not available. Considering the short timeframe and limited data and scope of projects, a rapid approach to evaluation had to be devised to complete the task.

\section{Application of CARP Model}

CBA6.1 is the prescribed model used to evaluate road projects in TMR. CBA6.1 enables a detailed evaluation of a wide range of projects and provides a wide range of flexibility in regards to traffic growth, traffic composition and road treatments that influence road conditions over the life of the project. Unfortunately, because of the lack of data, many of the data fields required by CBA6.1 to calculate results could not be populated rendering evaluations incomplete. CBA6.1 is designed for project evaluation rather than program evaluation and lacks the flexibility to combine large numbers of projects without the help of specially designed spreadsheets. Given the above-mentioned limitations and the tight timeframes, CBA6.1 was deemed not the most suitable model for the job. Instead, another model, CARP (Concise Analysis of Road Programs) (V1.0), developed in early 2012, was used as the primary model to evaluate the NB2 and BHAP funded projects. CARP (V1.0) was designed to rapidly evaluate programs or packages of projects with minimal compromise to the accuracy of the evaluation.

Literature suggests that there are a number of advantages of evaluating projects as a program of works. Such advantages include the recognition and evaluation of benefits of interdependent projects [3-6], improved transparency of project ranking and options analysis, clear identification of the net gains of a program and improved rigour of analysis [7]. CARP is designed to capture all of the above-mentioned benefits of program evaluation as well as provides the flexibility to evaluate projects individually.

CARP reduces time spent on collecting data by reducing the data requirements of each project. The project data that often require more time to acquire or are not normally available are generally not required in CARP. Project parameters requiring data for CARP are parameters with the highest sensitivity to RUC (road user cost) calculations. Parameters that RUC are most sensitive to are section length, AADT (average annual daily traffic), MRS (model road states) ${ }^{3}$, traffic growth rates, road alignments and traffic breakdown [8]. Of all the above-mentioned parameters, only traffic breakdown has been slightly compromised as the eight vehicle types used in CBA6.1 are reduced to just two vehicle types (cars and heavy vehicles). This compromise is small as traffic data for all eight vehicle types are rarely available, thus requiring assumptions to be made of that breakdown. Other data requirement omissions include surface and pavement types (all pavements are assumed to be sprayed seal), detailed maintenance schedules, flexible annual traffic growth rates and annual adjustments to roughness. The impact of excluding these parameters in most cases is minimal and in the case of most of the NB2 and BHAP funded projects, exact data were often not available. For models capable of providing detailed evaluation, such as CBA6.1, the above-mentioned parameters would be based on the best estimates of the analyst, which may not necessarily be consistent across all projects evaluated.

\section{Project Evaluation Methodology}

The project evaluation methodology applied to CARP to calculate RUC is consistent with Austroads and TMR CBA6.1 tool (CBA6). Austroads AP-R264/05 harmonisation paper [9] is the source for the vehicle operating cost and travel time cost algorithms applied to CARP. Accident cost algorithms are sourced from Austroads AP-R184 [10], RTA (Road Transport Authority) [11], TMR and Austroads Part 4: Guide to Project Evaluation [12]. Emission

\footnotetext{
${ }^{3}$ MRS defines the number of carriageways, seal width and accident rate for a specific road type [8].
} 
cost unit values per tonne of fuel consumed and the externality costs per vehicle travelled are sourced from Austroads Part 4: Guide to Project Evaluation [12].

The economic measures/indicators produced by CARP are the BCR, NBIR (net benefit investment ratio), NPV (net present value) and IRR (internal rate of return). The BCR is calculated according to the formula stated in Austroads [13] and the NBIR is calculated according to the Australian Transport Council [14] BCR formula, quoted as "NBIR" as stated by Campbell and Brown [15]. The application of discount rates to projects is flexible and users of CARP have an option to sensitivity test options with a range of discount rates. CARP also incorporates sensitivity testing around calculated benefits and costs to provide a maximum and minimum BCR or NBIR.
Table 1 provides a summary of the methodologies applied to calculate each RUC saving.

\section{Program Evaluation Methodology}

The program evaluation methodology should be ideally applied in two stages. The first stage involves the analysis of options to determine the optimal project option to be included in the program. The IBCR (incremental benefit cost ratio) or the INBIR (incremental net benefit investment ratio) is compared with the program cut-off $\mathrm{BCR} / \mathrm{NBIR}$ to determine the optimal option to be included in the program. The second stage involves the ranking of projects according to BCR or NBIR until the allocated budget is reached or the cut-off BCR/NBIR has been reached.

Table 1 Summary of methodology applied in CARP.

\begin{tabular}{|c|c|}
\hline Methodology Applied (benefits) & Applied to base and project case \\
\hline Travel time cost savings & $\begin{array}{l}(\text { Distance } \times \text { Unit Value/Operating Speed) } \times \text { AADT } \times 365.25 \text { (Operating speed is calculated using } \\
\text { freespeed arrays adjusted for horizontal, vertical alignment, sign posted speed and congestion) }\end{array}$ \\
\hline Vehicle operating cost savings & $\begin{array}{l}\text { Fuel + Oil + Tyre Wear + Maintenance \& Repair + Interest \& Depreciation (incorporates } \\
\text { horizontal \& vertical alignment factors, distance and operating speed, refer to CBA6 manual, } \\
\text { excludes lookup values for congestion impacts on VOC (vehicle operating costs)) }\end{array}$ \\
\hline Accident cost savings & $\begin{array}{l}\text { Accident costs calculated based on MRS accident rates adjusted for horizontal alignment and } \\
\text { Austroads unit values for accidents adjusted for operating speed }\end{array}$ \\
\hline $\begin{array}{l}\text { Accident cost savings from } \\
\text { intersection and minor road } \\
\text { treatments }\end{array}$ & $\begin{array}{l}\text { Accidents for projects with minor safety treatments and intersection upgrades are identified } \\
\text { according to the DCA (definition of classification of accidents) codes; } \\
\text { Treatment reductions are based on the RTA Accident Reduction Guide and Austroads Unit Values } \\
\text { for Road User Movements [11] }\end{array}$ \\
\hline Road closure cost savings & $\begin{array}{l}\text { Road closure savings consist of reduced waiting (same methodology as TTC (travel time costs) but } \\
\text { based on ADC (average duration of closure) and AATOC (average annual time of closure) instead } \\
\text { of } 365.25 \text { days, costs of diverting (reduced VOC + TTC + Accident) and not travelling costs } \\
\text { (reduced costs of not reaching destination calculated as loss of consumer surplus) }\end{array}$ \\
\hline Emission cost savings & $\begin{array}{l}\text { Emissions derived based on fuel consumed derived according to AP-R264/05; methodology } \\
\text { multiplied by Austroads costs of emissions (includes } \mathrm{CO}_{2}, \mathrm{CO}, \mathrm{NO}_{x} \text { and } \mathrm{SO}_{2} \text { ) }\end{array}$ \\
\hline Other externalities & $\begin{array}{l}\text { Externalities calculated per change in VKT (vehicle kilometres travelled) multiplied by Austroads } \\
\text { unit costs for externalities }\end{array}$ \\
\hline Generated traffic benefits & $\begin{array}{l}\text { Calculated as the gain in consumer surplus of generated traffic also known as rule of half } \\
\text { (perceived road user cost savings per existing road user } \times \text { generated road users } / 2 \text { ) [8] }\end{array}$ \\
\hline Other benefits & Benefits not calculated in CARP but manually entered by user \\
\hline \multicolumn{2}{|c|}{ Unit values and algorithms generally applied to benefits calculated } \\
\hline Unit values & $\begin{array}{l}\text { Unit values are provided by Austroads publication-Part 4: Project Evaluation Data (Updated } \\
\text { Road User Effects Unit Values) [12], all unit values are updated using the latest CPI (consumer } \\
\text { price index) }\end{array}$ \\
\hline Algorithms & Algorithms are provided by Austroads publication-AP-R264/05 [9] \\
\hline \multicolumn{2}{|l|}{ Methodology applied (costs) } \\
\hline Net construction/capital costs & Project case capital cost - base case alternative cost (P50 without escalation) \\
\hline Net increase in operating costs & $\begin{array}{l}\text { Annual project case operating costs — annual base case operating costs multiplied by evaluation } \\
\text { period }\end{array}$ \\
\hline
\end{tabular}

Source: Table 2, TMR [2]. 
The sequential and simultaneous approaches outlined by Davies [7] can be applied to the program evaluation using CARP. The sequential approach is based on the assumption that projects have been ranked prior to the evaluation and projects are evaluated in order of ranking. If the sequential approach is applied, the user of CARP can choose to select a predetermined ranking ${ }^{4}$ rather than the BCR or NBIR ${ }^{5}$. The simultaneous approach is based on the assumption that all projects in the program will proceed in the project case and none of the projects will proceed in the base case. Timing of projects is not considered in the simultaneous approach. For BHAP, the simultaneous approach was deemed most appropriate as the ranking of projects was yet to be finalised and project timings were unavailable. Using the simultaneous approach, the results of the program evaluation could be used as an input to project ranking within the program.

All projects evaluated as part of the BHAP using the CARP model were subject to a number of general assumptions. These assumptions are as follows:

- Evaluation period is 31 years (1 year of construction and 30 years of benefits);

- All projects are assumed for simplicity to be constructed simultaneously ${ }^{6}$;

- June 2012 prices have been applied to all benefits and costs;

- A discount rate of $7 \%$ has been applied to all projects;

- Sensitivity testing has been conducted at discount rates of $4 \%$ and $10 \%$;

- Results are sensitivity tested for 50\% increase or decrease in benefits;

- Results are sensitivity tested for $20 \%$ increase or

\footnotetext{
${ }^{4}$ Projects may have been ranked prior to the CBA using alternative methods such as multi-criteria analysis.

${ }^{5}$ The BCR has been presented in the BHAP report rather than the NBIR as the BCR was stated as the requirement from the TMR BHAP committee.

${ }^{6}$ Although this assumption is unrealistic, in order to compare project results, all projects need to be evaluated over the same period.
}

decrease in costs.

\subsection{Methodology Applied to Flood Immunity Projects}

The data provided for most of the flood immunity projects were limited to project costs, AATOC, maximum time of closure (Q50 flood events), road ID (identification) and chainage of the location of the project. The chainage and road ID were used to acquire road and traffic data from Chartview ${ }^{7}$. Even with the acquisition of data from Chartview, a number of parameters such as the length and road characteristics of the diversion routes and nature of road closures remained unknown.

For each project, two types of road closures were assumed, Q50 ${ }^{8}$ for serious flood events and Q2 for local flood events. For Q50 floods, maximum time of closure is assumed to equal the ADC and the AATOC is assumed to equal ADC/50. For local flood events, AATOC equals the AATOC provided minus the AATOC of the Q50 flood and the ADC equals AATOC multiplied by 2. Yeppen South Floodplain project (F13) was evaluated over three flood periods due to the availability of additional data.

Google maps was used to identify diversion routes during local flood events and no diversion routes were assumed available during Q50 flood events. The road characteristics of the diversion routes were held constant at a lower standard than that of the Bruce Highway.

Road user behaviour has not been specified for any of the flood immunity projects. Therefore, the assumption that road users opt for the least cost approach to reach a destination has been applied which is consistent with flooding methodology described by Davies [16].

The flood immunity program of works has been evaluated based on the assumption that all projects will be constructed in the project case and no projects

\footnotetext{
${ }^{7}$ Chartview is a road management information system database containing road characteristics and traffic data.

${ }^{8}$ Q50 Bridge is built to a standard where it will only flood during a 50-year or worse flood event.
} 
will be constructed in the base case. This method is appropriate for the initial evaluation of projects to determine a ranking based on BCR. To assess the impact of potential interrelatedness between projects, projects within close proximity of each other have been re-evaluated based on the assumption that not all interrelated projects are constructed in the project case. This approach has been adopted for Ingham to Cardwell Range Upgrade (F4) and Cattle and Francis Creek Upgrade (F5), and Brandon-Sandy Corner Upgrade, Burdekin River Upgrade and South of Home Hill Flood Immunity Upgrade. Stage 1 of the Burdekin Deviation (F8) is a possible alternative to the South of Home Hill Flood Immunity Upgrade and the upgrade of the existing Burdekin Bridge. Stage 2 of the Burdekin Deviation (F8) is a possible alternative to the proposed Brandon-Sandy Corner Upgrade and Burdekin River Upgrade to improve flood immunity while also allowing through traffic to bypass Ayr. The methodology applied to the Burdekin projects/options is explained in more detail in Section 4.4.1. For more information on program evaluation approaches for interrelated projects please refer to the conference paper of Davies [7].

\subsection{Assumptions Applied to the Flood Immunity} Projects

Given the limited availability of data, a number of assumptions have been made and applied consistently across all flood immunity projects:

- Assets of a life of 100 years (mostly bridges) are apportioned $20 \%$ of capital costs;

- The residual value of the bridges is calculated as follows: Capital Cost $\times 20 \% \times(100 \mathrm{yr}-30 \mathrm{yr}) / 100 \mathrm{yr}$;

- With the exception of Yeppen South Floodplain, which also includes Q20 flood events, only Q2 and Q50 flood events have been considered;

- Average maintenance cost are assumed to decrease by $\$ 100,000$ per $\mathrm{km}^{9}$;

${ }^{9}$ Maintenance costs are based on information provided by the regions.
- Diversion routes have constant generic road characteristics;

- Lengths of diversion and improved routes have been taken from Google maps;

- Existing traffic on diversion routes is assumed to be unaffected by diverting traffic;

- All road upgrades are assumed to be of engineering standards (MRS of 15);

- For projects involving deviations, all vehicles are assumed to use the deviation;

- For the Tiaro Bypass, $75 \%$ of traffic is assumed to be through traffic and $24 \%$ of the through traffic is heavy vehicles;

- For proposed projects in close proximity of each other, $50 \%$ of the road closure time at the project site with the lowest closure times is assumed to be resolved by the upgrade of both projects;

- Some interrelated projects are combined into one evaluation when benefits for each project are not clearly divisible (F4, F5 and Burdekin Deviation Projects).

\subsection{Results of the Flood Immunity Projects}

Tiaro Bypass is the only flood immunity project with a NPV greater than 0 and a BCR greater than 1 . To maximise the NPV of the program, the Tiaro Bypass should be the only project to be included in the program. A number of other projects with BCRs below 1 could be included in the program without pulling the overall NPV of the program below 0 . Table $2^{10}$ contains the projects proposed to be included in the program based on the strategic economic analysis described in this report. The Burdekin Deviation (F8) described in the Burdekin Deviation options analysis section of the methodology documentation is also included in the results in Table 2 (see Appendix A for the NPV and BCR for all projects proposed in the BHAP flood immunity program).

\footnotetext{
${ }^{10}$ Projects are recommended based on obtaining a BCR above 1 for the Flood Immunity Program of Works rather than each project achieving a BCR above 1.
} 
Table 2 Results of program by project (recommended projects).

\begin{tabular}{|c|c|c|c|c|c|c|c|}
\hline Rank & Project name & NPV $(\$)$ & BCR & Benefits sensitivity (\%) & Costs Sensitivity (\%) & Min BCR & Max BCR \\
\hline 1 & Tiaro Bypass (F16) & $240,839,436$ & 6.20 & 50 & 20 & 2.46 & 12.54 \\
\hline 2 & Burdekin Deviation (F8) & $-377,662,248$ & 0.74 & 50 & 20 & 0.31 & 1.38 \\
\hline 3 & Meunga/Sunbeam/Lily (F3) & $-27,037,566$ & 0.65 & 50 & 20 & 0.27 & 1.23 \\
\hline 4 & Yeppen South (F13) & $-149,309,621$ & 0.49 & 50 & 20 & 0.20 & 0.92 \\
\hline \multirow{3}{*}{ Total } & Without Burdekin Deviation & $64,492,249$ & 1.16 & 50 & 19 & 0.48 & 2.17 \\
\hline & With Burdekin Deviation & $-286,169,999$ & 0.84 & 50 & 20 & 0.35 & 1.58 \\
\hline & $\mathrm{F} 3, \mathrm{~F} 8$ and $\mathrm{F} 16$ & $-163,467,305$ & 0.89 & 50 & 20 & 0.37 & 1.67 \\
\hline
\end{tabular}

Source: TMR [2].

For the sensitivity analysis, benefits of all projects are subject to a sensitivity of plus or minus $50 \%$ due to lack of data. Costs are subject to a sensitivity of plus or minus $20 \%$, which is a standard sensitivity test for most evaluations conducted by TMR. The difference between the minimum and maximum BCRs for most projects in Table 2 is quite large. A minimum BCR of greater than 1 even at this strategic level indicates a project is definitely viable. A maximum $\mathrm{BCR}$ of greater than 1 indicates that a project may become economically viable if improved or more detailed data are used. A maximum BCR of less than 1 indicates that the project is highly unlikely to become economically viable even with improved data, and these projects may be included in a program if they indirectly contribute to the value of the program as a whole.

\subsection{Methodology Applied to Capacity Projects}

For the flood immunity projects, a standard methodology could be easily applied across all projects but for the capacity projects, such a methodology was not possible as the projects varied considerably in nature. Therefore, the methodologies of only a few select projects have been included in this paper. The selected projects demonstrate the interrelated nature of projects that are within close proximity to each other. The BCR and NPV of the capacity projects are included in Appendix A.

4.4.1 Burdekin Deviation Methodology

The Burdekin Bridge, located along the Bruce Highway near Home Hill and Ayr, has height and width restrictions that prevent some of the heavy vehicles from crossing the Burdekin River. These heavy vehicles are forced to permanently divert to cross the Burdekin River at an alternative location. Heavy vehicles that cannot cross the Burdekin Bridge travelling between Mackay and Townsville are assumed to travel an extra $252 \mathrm{~km}$ to avoid the Burdekin Bridge. Two alternatives have been proposed to resolve this problem: constructing a new bridge and approaches (Stage 1 of the Burdekin Deviation) or upgrading the existing bridge.

Flooding occurs at Plantation Creek, Sheep Station Creek and South of Home Hill. Brandon-Sandy Corner, Burdekin River Upgrades, and South of Home Hill flood immunity project or Stage 1 of the Burdekin Deviation will improve the flood immunity of the Bruce Highway for all road users. Alternatively, Stage 2 of the Burdekin Deviation will improve the flood immunity of the Bruce Highway, benefiting through traffic more than local traffic. Stage 2 of the Burdekin Deviation provides additional benefits by allowing through traffic to bypass Ayr.

Stage 1 of the Burdekin Deviation will resolve the partial road closure to $10 \%$ of the heavy vehicles passing through Ayr (vehicles that do not meet the existing bridge specifications). In the base case, cars and $90 \%$ of the heavy vehicles cross the existing bridge, while $10 \%$ of the heavy vehicles travel an extra $252 \mathrm{~km}$ to cross the Burdekin River. Stage 2 of the Burdekin Deviation has been treated as a bypass that improves flood immunity and capacity. All other assumptions applied to other flood immunity projects 
hold true for the bypass. The bypass also includes railway crossings, and the benefits of these crossings have been excluded from the analysis due to lack of crash related data.

The above treatments have been bundled into nine project options, and these options are as follows:

(1) constructing only Stage 1 of the Burdekin Deviation;

(2) constructing both Stages 1 and 2 of the Burdekin Deviation (F8);

(3) constructing Stage 1 of the Burdekin Deviation, Brandon-Sandy Corner and Burdekin River Upgrades;

(4) constructing only Brandon-Sandy Corner, Burdekin River and South of Home Hill Upgrades;

(5) constructing Stages 1 and 2 of the Burdekin Deviation and Brandon-Sandy Corner and Burdekin River Upgrades;

(6) upgrading existing Burdekin Bridge;

(7) upgrading existing Burdekin Bridge and Brandon-Sandy Corner, Burdekin River and South of Home Hill Upgrades;

(8) upgrading existing Burdekin Bridge and Stage 2 of the Burdekin Deviation;

(9) upgrading existing Burdekin Bridge, Stage 2 of the Burdekin Deviation and Brandon-Sandy Corner, Burdekin River and South of Home Hill Upgrades.

\subsubsection{Cooroy to Curra (Section A)}

Cooroy to Curra (Section A), located approximately 20 30 km south of Gympie [17], has been evaluated as a simple duplication from a two-lane highway to a four-lane highway section of road. Increased capacity results in benefits to travel time and reductions in vehicle operating costs. The additional capacity and cost reductions in travel is assumed to generate traffic. A capacity constraint has been applied to the base case, and this capacity constraint will prevent the traffic volume from exceeding the capacity of the road. The project case has a larger capacity than the base case. Therefore, traffic volume in the project case will exceed that of the base case. The additional traffic is treated as generated traffic.

\subsubsection{Cooroy to Curra (Section C)}

Cooroy to Curra (Section C), located approximately 10 20 km south of Gympie [17], has been treated as a duplication and realignment of the Bruce Highway that also improves flood immunity. This project is subject to the same assumptions as the flood immunity projects (see Section 4.1 for flood immunity methodology and Section 4.2 for assumptions applied to the flood immunity projects). If Section $\mathrm{D}$ is not constructed, the flood immunity benefits for Section $\mathrm{C}$ are removed from the evaluation (see Appendix A for both sets of results). The methodology applied to the duplication of Section $\mathrm{C}$ is similar to the methodology proposed for Section A, but also includes a reduction in section length and a change in a curvy horizontal alignment to a straight horizontal alignment. The improved alignment will enable higher operating speeds, reduced tyre wear and fuel consumption, and improved safety. The reduction in section length will reduce road user costs proportionate to the percentage reduction in section length.

\subsubsection{Cooroy to Curra (Section D)}

Cooroy to Curra (Section D), located through Gympie and up to $20 \mathrm{~km}$ north of Gympie [17], has been evaluated as a realignment and duplication of the Bruce Highway. The project also includes flood immunity benefits similar in nature to Section C. These flood immunity benefits were excluded to avoid double counting, as both Sections C and D are required to be upgraded to improve the flood immunity of the link through Gympie.

\subsubsection{Wide Bay Highway Interchange}

The proposed Wide Bay Highway T-Intersection Upgrade, located $12 \mathrm{~km}$ north of Gympie [18], has been evaluated as the replacement of the current at-grade intersection with an overpass to enable traffic turning onto the Bruce Highway from the Wide Bay Highway to move freely. The Wide Bay Interchange has been evaluated twice, and one evaluation is subject to the assumption that Section D of the Cooroy to Curra Upgrade proceeds while the other 
evaluation is subject to the assumption that this Cooroy to Curra (Section D) does not proceed. The construction of Cooroy to Curra (Section D) will improve the base case, as the traffic along the Bruce Highway will be substantially reduced thus reducing delays to vehicles turning right onto the Bruce Highway.

Safety benefits for the entire intersection have been evaluated using DCA codes. Treatments and the travel time cost and vehicle operating cost savings have been evaluated for vehicles turning onto the Bruce Highway (AADT against gazettal). Distance travelled through the intersection has been halved in the project case as a proxy to simulate delays and vehicle operating costs accrued by vehicles waiting at the intersection. Delays have also been reduced by $25 \%$ in the base case if Cooroy to Curra (Section D) proceeds to simulate the impact of reduced traffic volumes along the Bruce Highway (old).

\subsubsection{Boundary Road Interchange Upgrade}

The Boundary Road Interchange, located at the interchange of Boundary Road and the Bruce Highway south of Burpengary and $10 \mathrm{~km}$ north of Pine River [19], requires upgrading to accommodate for the increasing traffic flows from local communities and facilitate the implementation of the Managed Motorways' upgrade described in Section 4.4.7. This project has been evaluated using SIDRA ${ }^{11}$ data and accident data collected at the project site. The SIDRA data were used to determine peak traffic volume, average travel time for peak periods, average operating speed and average distance travelled through the intersection ${ }^{12}$. Average distance travelled is adjusted in the project case based on travel time and used as a proxy to determine travel time costs and VOC. Average distance is chosen over average speed

\footnotetext{
${ }^{11}$ SIDRA Intersection is a well-known software package used worldwide for intersection capacity, level of service and performance analysis by traffic design, operations and planning professionals [20].

${ }^{12}$ VOC have been calculated within CARP as the SIDRA fuel consumption data were not provided with the other SIDRA data, which were recorded in a spreadsheet.
}

as a proxy as distance has a simple multiplicative relationship to cost calculation, whereas speed influences both VOC and accident cost calculations in CARP. Average speed reductions in the base case are due to start-stop rather than a constant speed, therefore would artificially distort accident cost calculations. The treatment of engineering standard grade separation is applied to evaluate accident cost savings using DCA code accident reduction factors.

\subsubsection{Managed Motorways-Gateway Motorway}

"Managed Motorways" is the term used to describe urban motorways that have intelligent information [21]. The proposed ITS (intelligent transport system) ${ }^{13}$ is expected to increase capacity of the Bruce Highway by up to $25 \%$ during peak periods [21]. The Bruce Highway (road ID: 10A) from chainage 0 to $23 \mathrm{~km}$ has a MRS of 22 (three lanes in either direction). To simulate an increase in capacity of $25 \%$, the MRS of the project case has been assumed to be increased to 23 (four lanes in either direction). All other road characteristics are assumed unchanged. In order for the ITS to be implemented, Boundary Road Interchange requires upgrading as described in Section 4.4.6. The Anzac Avenue Upgrade, though not evaluated as part of BHAP due to undefined scope, also requires upgrading for the full benefits of ITS to be realized. The costs and benefits of Boundary Road Interchange Upgrade have been included in this analysis, whereas cost and benefits from the Anzac Avenue project have been excluded.

\subsubsection{Results of the Capacity Projects}

The results of the capacity projects are mixed with some projects obtaining high BCRs, such as Managed Motorways (Gateway Motorway) and Mackay Ring Road Stage 1, while other projects obtained low BCRs, such as Bowen Intersection Upgrade and Cairns SAC (Southern Access Corridor) Stage 3. AADT, VCR (volume capacity ratio), traffic growth rate and capital

\footnotetext{
${ }^{13}$ ITS covers any technology applied to transport and infrastructure to transfer information between systems for improved safety, productivity and environmental performance [22].
} 
cost are the key factors in determining the NPV and BCR of most capacity projects. Section 6 highlights some other factors that may have distorted results. The capacity projects have been subject to the same sensitivity tests as the flood immunity projects described in the Section 4.2. The complete results of the capacity projects are included in Table A1 in Appendix A.

\subsection{Methodology Applied to Safety Projects}

The safety projects are separated into overtaking lane projects, and road widening and shoulder seal projects. The methodologies applied to the overtaking lane projects vary considerably from road widening and shoulder seal projects. Overtaking lane projects are more complicated to evaluate as they not only improve safety but also travel time. Overtaking lanes also influence upstream ${ }^{14}$ and downstream areas ${ }^{15}$ of approximately $3 \mathrm{~km}$ and $5 \mathrm{~km}$, respectively. The overtaking lane is expected to improve safety in the upstream area as faster vehicles will wait to safely overtake using the overtaking lane. The overtaking lane will improve operating speed and safety in the downstream area as faster vehicles would have passed slower vehicles using the overtaking lane and are not expected to encounter more heavy vehicles for an average distance of $5 \mathrm{~km}$. The road widening and shoulder seal projects are almost entirely focused on improving safety with limited impact on other benefit categories. The road widening and shoulder seal projects as part of BHAP are not clearly defined as projects but rather the upgrade of any sections of the Bruce Highway not currently at the vision width (10 m seal).

\subsubsection{Overtaking Lane Projects}

One hundred and eighty-nine overtaking lane projects have been proposed as part of the BHAP. The short timeframes and the insufficient information to

\footnotetext{
${ }^{14}$ The upstream area is the section of road immediately preceding the overtaking lane [8].

${ }^{15}$ The downstream area of the overtaking lane is the section of road immediately following the overtaking lane [8].
}

the exact location of each overtaking lane prompt the use of a link evaluation approach rather than the evaluation of each individual overtaking lane. Ten links are identified between Gympie and Cairns. The total proposed lengths of the overtaking lanes, downstream and upstream areas per link were combined into one evaluation. The vision distance between overtaking lanes is determined based on the average AADT per link.

The overtaking lanes are spaced according to the AADT on the highway. If the AADT is between 2,000 and 4,000, the overtaking lanes are spaced $20 \mathrm{~km}$ apart, and if the AADT is between 4,000 and 6,000, the overtaking lanes are spaced $10 \mathrm{~km}$ apart, and if AADT is greater than 6,000, the overtaking lanes are spaced $5 \mathrm{~km}$ apart. The overtaking lanes have an assumed section length of $1.2 \mathrm{~km}$ and have upstream areas of $3 \mathrm{~km}$ and downstream areas of $5 \mathrm{~km}$. For sections with AADT of greater than 6,000 vehicles, it is assumed that there are no upstream and downstream benefits that are reduced to an area of just $3.8 \mathrm{~km}$. The parameters of the road and traffic data applied to each link are weighted averages for the whole link. The results for each link are given in Table 3.

The results indicate that the viability of the links is almost solely dependent on the weighted average AADT for the link. Other parameters such as vertical and horizontal alignment of the links do not vary due to averaging. The capital costs for each overtaking lane are also assumed constant for the entire length of the Bruce Highway.

\subsubsection{Widening/Shoulder Seals}

Widening of shoulder seals was proposed for the length of the Bruce Highway between Brisbane and Cairns for sections of road that did not meet the vision seal width of $10 \mathrm{~m}$ (MRS of 14). Of the $1,667 \mathrm{~km}$ of the Bruce Highway between Brisbane and Cairns, $404 \mathrm{~km}$ did not meet the vision seal width. The distance of $404 \mathrm{~km}$ was calculated by summating all the scattered sections of the Bruce Highway with narrow seals. The safety benefits for the widened road 
Table 3 Results of the overtaking lane link evaluations.

\begin{tabular}{llrll}
\hline Link & Description & Cost $(\$)$ & NPV $(\$)$ & BCR \\
\hline Link 1 & Cairns-Innisfail & $131,520,000$ & $-61,571,472$ & 0.53 \\
Link 2 & Innisfail-Townsville & $102,750,000$ & $-82,618,785$ & 0.20 \\
Link 3 & Townsville Urban & $32,880,000$ & $110,251,473$ & 4.35 \\
Link 4 & Townsville-Bowen & $94,530,000$ & $-74,859,079$ & 0.21 \\
Link 5 & Bowen-Mackay & $82,200,000$ & $-67,084,031$ & 0.18 \\
Link 6 & Mackay-St Lawrence & $45,210,000$ & $-33,639,177$ & 0.26 \\
Link 7 & St Lawrence-Rockhampton & $106,860,000$ & $-87,481,252$ & 0.18 \\
Link 8 & Rockhampton-Gin Gin & $115,080,000$ & $312,937,848$ & 3.72 \\
Link 9 & Gin Gin-Maryborough & $53,430,000$ & $-37,284,973$ & 0.30 \\
Link 10 & Mary Borough-Gympie & $12,330,000$ & $-2,122,820$ & 0.83 \\
\hline
\end{tabular}

Source: Table 5, TMR [2].

sections were calculated using accident rates per mVKT (million vehicle kilometres travelled) according to the MRS of the section. In the base case, the MRS of the narrow sections of road ranged between 10 and 12. Table 4 shows the distance in kilometres for the sections of road with MRS 10, 11 and 12 with their corresponding accident rates per mVKT and it also contains the accident rate for MRS 14 to be applied to the project case.

The combined NPV and BCR for the road widening and shoulder seal projects at a discount rate of $7 \%$ were $\$ 41,549,300$ and 1.12 , respectively. The benefits of the road widening and shoulder sealing projects are likely to be understated, as accident cost savings were the only benefits considered, and benefits from improved capacity and smoother road surface have not been included due to lack of specific project information.

\section{Results of the Program}

If all projects are assumed to be included in the BHAP, the program will not be economically viable as the NPV falls below $0^{16}$. Table 5 contains the results of the program CBA when all projects (BHAP and NB2 funded projects) are included.

\footnotetext{
${ }^{16}$ The results covered in this section are just a broad overview of the program. A detailed discussion of the benefit and cost streams of each project or even the program as a whole would require another paper. The TMR BHAP report contains more information regarding the results.
}

If projects are ranked according to $\mathrm{BCR}$ and a cut-off BCR of 1 is established to eliminate the projects deemed economically unviable based on the analysis, the program will have greatly improved results as shown in Table 6.

If a cut-off BCR of 1 is applied, the program will consist of only one flood immunity project, eight capacity projects, two of the 10 links for the overtaking lanes and the road widening program. Considering the rapid nature of the program evaluations, applying a cut-off BCR of 1 may eliminate some of the projects that would have obtained BCRs above 1 if analyses had been conducted in more detail. Another approach would be to lower the cut-off BCR to less than 1. Nominating

Table 4 Road widening/shoulder data inputs.

\begin{tabular}{lll}
\hline MRS & Section length $(\mathrm{km})$ & Accident rate $(\mathrm{mVKT})$ \\
\hline 10 & 5 & 0.3785 \\
11 & 9 & 0.3257 \\
12 & 390 & 0.2817 \\
14 & 404 (project case) & 0.2289 \\
\hline
\end{tabular}

Source: Table 1, TMR [23].

Table 5 Results of BHAP according to programs.

\begin{tabular}{lrl}
\hline Program & NPV $(\$)$ & BCR \\
\hline Flooding & $-1,983,825,834$ & 0.49 \\
Capacity & $-1,765,183,215$ & 0.78 \\
Overtaking lanes & $-23,472,268$ & 0.97 \\
Road widening & $41,549,300$ & 1.12 \\
\hline Total & $-3,730,932,017$ & 0.71 \\
\hline
\end{tabular}

Source: Table 11, TMR 2013. 
Table 6 Results of BHAP according to programs (cut-off BCR is 1).

\begin{tabular}{lrl}
\hline Program & \multicolumn{1}{c}{ NPV (\$) } & BCR \\
\hline Flooding (Tiaro Bypass) & $240,839,436$ & 6.20 \\
Capacity & $1,433,500,000$ & 2.00 \\
Overtaking lanes (Links 3 and 8) & $423,189,321$ & 3.86 \\
Road widening & $41,549,300$ & 1.12 \\
Total & $2,139,078,057$ & 2.13 \\
\hline
\end{tabular}

Table 7 Results of BHAP according to programs (cut-off BCR is 0.6).

\begin{tabular}{lrl}
\hline Program & NPV (\$) & BCR \\
\hline Flooding (F3, F8 and F16) & $-163,467,305$ & 0.89 \\
Capacity & $747,410,000$ & 1.16 \\
Overtaking lanes (Links 3, 8 and 10) & $64,008,984$ & 1.10 \\
Road widening & $41,549,300$ & 1.12 \\
\hline Total & $689,500,979$ & 1.10 \\
\hline
\end{tabular}

such a cut-off BCR creates a dilemma given that a cut-off BCR that is too low will reduce the overall program NPV to below $0^{17}$ and a cut-off BCR, which is too high, could result in the exclusion of some projects with underestimated benefits. A cut-off BCR of 0.6 allows for the inclusion of projects or bundles of interrelated projects that could become viable if subjected to more detailed analysis whilst not reducing the NPV of the program to below 0 . Table 7 contains the results of the program if a cut-off BCR of 0.6 is selected.

If a cut-off BCR of 0.6 is used instead of 1 , an additional two flood immunity projects, five capacity projects and one overtaking lane link can be included in the program without reducing the NPV of the program to below 0 . A cut-off BCR of below 1 had not been proposed in the BHAP report but has been raised in this paper as another possible method of selecting projects for BHAP and/or for future more detailed evaluation. Eventually, when a fixed budget is decided for the BHAP, a cut-off BCR can be determined based on the last project ranked according to BCR to exhaust the budget. The prescribed cut-off BCR should be above 1 once more detailed analysis

\footnotetext{
${ }^{17}$ Maintaining a program NPV of greater than 0 is important to demonstrate the overall viability of the program from a strategic approach even though the benefits of some of the projects are understated.
}

has been conducted.

\section{Limitations and Questionable Assumptions}

The purpose of the BHAP program evaluation was to provide strategic guidance to the viability of a large number of proposed projects rather than an accurate CBA of all projects. The time and resources were not available at the time of the analysis to produce comprehensive CBAs of the standard to be included in a detailed funding submission. Projects that performed favourably or have been identified as having insufficient data for an adequate evaluation at this time will be revisited. Projects that have performed poorly in the strategic analysis and the limitations in data which are not deemed to significantly change the results are not expected to undergo a more detailed CBA.

The requirements of the evaluations depend on what data are available. This approach limits the ability of decision makers to compare projects in the program. The Rockhampton North Access Upgrades are examples of projects with limited available information regarding scope and no available intersection modelling. Whereas, projects such as MacArthur and Milton Black Drive Intersection upgrades had detailed intersection modelling and well documented scope. The projects with more complete information had higher BCRs than those with less complete information, but it is difficult to ascertain how responsible the lack of information is for the differences in BCRs. Therefore, some of the comparisons between projects cannot be relied upon for prioritizing projects within the program. Another clear limitation in respect to the overtaking lanes and road widening projects is that projects were not individually evaluated but instead the links where these projects were intended to be located. A link may have a very low NPV, but there may be a number of projects at locations where the NPV could be significantly higher due to high traffic volumes, more 
heavy vehicles or steeper terrain. For links with high NPVs, there could be projects at locations where the NPV could be substantially lower due to the close proximity of existing overtaking lanes or the proximity of key turn offs for some heavy vehicles.

Another key limitation is the model. BHAP was the first time CARP had been applied to an evaluation. The model had been tested using sample evaluations and projects that had been evaluated using TMR's standard CBA model, CBA6, but not all aspects of the model had been carefully tested. There is a potential for errors in calculations that may not be identified when results are reviewed. The complexity of some of the bypasses and diversion projects would not have been adequately captured in CARP. CARP is limited to averages of sections of road and if longer sections of road had varying characteristics, the impacts of these variances will not be recognized in the evaluation. The intersection component of CARP is very basic and relies on changes in speed for travel time cost savings and start-stop effects on fuel consumption are not considered. The intersection component of the model is designed mostly to cater for safety upgrades rather than capacity upgrades.

Possibly, the greatest area of concern relates to the scopes of projects. Many of the BHAP projects do not have clearly defined scopes, thus requiring the team, with advice from the Queensland Regions, to make a number of simplifying assumptions. Data collection is an ongoing task during the evaluation process, consequently in order for the team to progress through the evaluations in a timely fashion, proxies (and in some cases dummy values) were inserted into evaluations. The proxies used are rules of thumb around inputs such as maintenance per kilometre or the years in which future maintenance is likely to be implemented in both the base and the project cases. The dummy values are nothing more than deductions using the best information available. For example, some of the lengths and even locations of some project sites are approximated based on early drafts of projects. The dummy values are not intended to remain in the final results but to just merely hold the evaluation together until better defined scopes are available.

A major area of note and inconsistency was that a number of projects to be included in the BHAP report had been previously evaluated. As mentioned earlier in the paper, the NBP1 funded projects had already been evaluated but were still required to be included as part of BHAP for completeness. The NBP1 project evaluations had been evaluated using numerous and often inconsistent methodologies. Unfortunately, the documentation of the NBP1 projects was not sufficient to harmonize the methodology applied to those projects with each other or the BHAP projects evaluated using CARP. In the final report submitted, all projects were included, but this paper does not cover the scope of the methodology applied to the NBP1 projects.

The detail applied to the estimation of capital costs for each project varied for a number of projects. Some projects only had very raw strategic estimates, while others had $\mathrm{P} 50^{18}$ estimates and some had $\mathrm{P} 90^{19}$ estimates. Often only one estimate was available for each project, giving the team no choice but to apply that estimate. P50 estimates minus escalation are typically applied to CBAs as the closest expected value of capital costs. Projects with strategically estimated capital costs are likely to have more favourable results as capital costs are likely to have been underestimated due to lack of inclusion of contingencies. Projects with P90 estimates are likely to have less favourable results as capital costs include contingencies beyond their expected value. The BHAP report informed decision makers that results were biased in favour of projects with strategic estimates and were biased against those with P90

\footnotetext{
${ }^{18} \mathrm{P} 50$ estimate is an estimate with a $50 \%$ confidence of not being exceeded at project completion, while not being conservative [24].

${ }^{19} \mathrm{P} 90$ estimate is an estimate with a $90 \%$ confidence of not being exceeded at project completion, while not being conservative [24].
} 
estimates by including the type of estimate applied to each evaluation. The sensitivity tests of increasing and decreasing costs by $20 \%$ were applied to all projects for consistency. For projects with P90 estimates, the $20 \%$ increase is likely to produce unreasonably high costs. For projects with raw strategic estimates, the $20 \%$ reduction is likely to produce unreasonably low costs. Appendix B contains notes describing the type of estimate applied to each project

The limitations of the BHAP evaluation are numerous and cannot be fully covered in this paper but the most important point to consider is the purpose of the evaluations. If the BHAP evaluation can be used as a useful strategic input into the future planning of the upgrade to the Bruce Highway, many limitations stated in this paper are not a major concern as long as the results produced are not completely inaccurate. The use of CARP for the BHAP and NB2 funded projects provides some consistency to allow some comparison between projects. The accuracy of the BHAP evaluations will be revealed once the selected projects are evaluated in greater detail. If the CBA team is involved in this process, the applied methodologies to the BHAP can be reviewed and improved upon for future such program evaluations.

\section{Application of the Advice Provided by the BHAP Report}

On April 24, 2013, there was a media release outlining the Australian Government's new commitments to the Bruce Highway [25]. Of the 18 projects announced as new commitments, 17 were evaluated using the methodology discussed in this paper. The 17 projects to be funded and their respective NPVs and BCRs calculated using CARP are given in Table 8.

The NPVs and BCRs presented in Table 8 are current as of October 2012. Most of the projects in Table 8 are currently or will be undergoing CBAs that are more detailed. Therefore, the results presented in this paper will not necessarily correspond to those included in the final funding submissions. The selection of projects to be funded is in partial agreement to the advice provided from the BHAP report. Projects such as Managed Motorways (Gateway Motorway), Cooroy to Curra Section C, Mackay Ring Road Stage 1 and Mackay Northern Access Upgrade have been included. Projects such as Tiaro Flood Immunity and Tinana Interchange would have been economically viable inclusions. Some of the

Table 8 Projects evaluated as part of BHAP announced as New Federal Government Commitments.

\begin{tabular}{llrl}
\hline Project ID & Project name & NPV $(\$)$ & BCR \\
\hline F5 & Flood Immunity (Cattle and Frances Creek) & $-109,714,804$ & 0.21 \\
F6 & Flood Immunity (Haughton River) & $-397,283,384$ & 0.11 \\
F9 & Flood Immunity (Yellow Gin Creek) & $-43,725,950$ & 0.09 \\
F10 & Flood Immunity (Sandy Gully Creek) & $-70,035,637$ & 0.07 \\
F13 & Flood Immunity (Yeppen South Floodplain) & $-149,309,621$ & 0.49 \\
C3 & Cairns SAC Stage 2 - Robert Rd. to Foster Rd. & $-57,478,893$ & 0.01 \\
C21 & Mackay Northern Access Upgrade & $12,370,545$ & 1.12 \\
C24 & Mackay Ring Road Stage 1 & $606,633,413$ & 2.35 \\
C30 & Rockhampton North Access Upgrade 2 & $-80,876,381$ & 0.15 \\
C31 & Rockhampton North Access Upgrade 1 & $-76,000,000$ & 0.04 \\
C45 & Cooroy to Curra Section D & $-505,185,103$ & 0.75 \\
C47 & Cooroy to Curra Section C & $376,668,653$ & 1.63 \\
C51 & Caloundra Road to Sunshine Motorway & $-1,408,359,418$ & 0.25 \\
C54 & Managed Motorways (Gateway Motorway) & $370,704,869$ & 2.72 \\
- & Overtaking Lanes (Caboolture to Cairns) & $-23,472,268$ & 0.97 \\
- & Pavement Widening (Lawrence to Bowen) & & 1.12 \\
- & Pavement Widening (Home Hill to Ingham) & & 1.12 \\
\hline
\end{tabular}

Source: TMR 2013 [2]. 
projects with low BCRs such as the Rockhampton North Access projects did not have peak traffic data, therefore, benefits from improved traffic flow at peak times were not incorporated in the CBA.

\section{Conclusions}

The BHAP program evaluation is unique in many ways. The sheer number of projects to evaluate in the space of such a short time was very challenging. The limited scope and data required team members to come up with innovative methods of evaluating some projects. These methods should be validated by further analysis. For the purpose of this exercise, results obtained should prove to be a rough indicator of the viability of projects and provide an indication of where projects could be prioritised within the program.

One of the important advantages of evaluating projects as part of a program is that the interrelatedness between projects can be identified. This was the case for some of the flood immunity and capacity projects located within close proximity of each other. If these projects had been evaluated in isolation, the impacts projects have on each other would not have been identified.

Excluding the NBP1 projects, the methodology applied to the evaluations is consistent enough for rough comparisons, as projects were evaluated using the same model (CARP V1.0), to be made between projects and allow projects to be ranked according to BCR. If an assumed cut-off BCR is applied, a proposed list of economically viable or close to economically viable projects can be short-listed for further analysis. Normally, a cut-off BCR of 1 or greater than 1 [26] is suggested, given the rapid nature of the evaluations, the recommendation of this paper is that the cut-off BCR should be lowered to account for the benefits excluded from the projects. When projects are re-evaluated with sufficient data and the budget is more clearly defined, the cut-off BCR should be raised to reflect the most efficient use of that budget.

Most projects evaluated did not obtain NPVs greater than 0 . This is partly related to the rapid nature of the analysis and the unavailability of data that might have produced larger benefit streams. Some projects did not produce NPVs greater than 0 simply because the traffic volumes were not high enough, the proposed project did not fully address the problem or the capital costs were too high. The positive response from both State and Federal Governments is a good indication that the work on the BHAP program evaluation is being applied and contributing to investment decisions. The ongoing more detailed CBAs of projects will provide an indication of how close the strategic analysis discussed in this paper has come to providing accurate results.

\section{Acknowledgments}

The author would like to thank his colleagues: Mark Best, Mathew Singh, Shane Campbell, Alison Kent, Michael Ahlberg and Robin Murray for the many hours of dedicated hard work that they put into completing the BHAP Program Evaluation.

\section{References}

[1] Transport and Main Roads. 2012. Bruce Highway Action Plan "Out of the Crisis". Brisbane: Queensland Government.

[2] Transport and Main Roads. 2013. Benefit Cost Analysis-Bruce Highway Action Plan Economic Evaluation. Brisbane: Queensland Government. (unpublished)

[3] Nemhauser, G. L., and Ullmann, Z. 1969. "Discrete Dynamic Programming and Capital Allocation.” Management Science 15 (9): 494-505.

[4] Gear, T. E., and Cowie, G. C. 1980. "A Note on Modeling Project Interdependence in Research and Development.” Decision Science 11: 738-48.

[5] Fox, G. E., Baker, N. R., and Bryant, L. J. 1984. "Economic Models for R\&D Project Selection in the Presence of Project Interactions.” Management Science 30: 890-902.

[6] Tao, X., and Schonfeld, P. 2006. "Selection and Scheduling of Interdependent Transportation Projects with Island Models.” In Transportation Research Record: 
Journal of the Transportation Research Board, No. 1981, Transportation Research Board of the National Academies, 133-41.

[7] Davies, W. 2012. "Road Program Evaluation: Assessing the Bigger Picture.” Presented at 25th ARRB Conference, Perth, Australia.

[8] Transport and Main Roads. 2011. Cost-Benefit Analysis Manual: Road Projects. Brisbane: Queensland Government.

[9] Austroads. 2005. Economic Evaluation of Road Infrastructure Investment Proposals: Harmonisation of Non-urban Road User Cost Models. Austroads.

[10] Austroads. 2001. Economic Evaluation of Road Investment Proposals: Improved Predictions Model for Road Crash Savings. Austroads.

[11] Road Transport Authority. 2004. Accident Reduction Guide. Australia: New South Wales Government.

[12] Austroads. 2012. Guide to Project Evaluation-Part 4: Project Evaluation Data (Updated Road User Effects Unit Values). Sydney: Austroads.

[13] Austroads. 1996. Benefit Cost Analysis Manual. Sydney: Austroads.

[14] Australian Transport Council. 2006. National Guidelines for Transport Systems Management in Australia, 5 Background Materials. Canberra: Commonwealth of Australia.

[15] Campbell, H. F., and Brown, R. P. C. 2007. Benefit-Cost Analysis Financial and Economic Appraisal Using Spreadsheets. Cambridge: Cambridge University Press.

[16] Davies, W. 2011. "Advanced Methods of Evaluating Benefits from Improved Flood Immunity in Queensland.” Presented at Australasian Transport Research Forum 2011, Adelaide, Australia.

[17] Transport and Main Roads. 2012. Bruce Highway
Upgrade (Cooroy to Curra). Brisbane: Queensland Government. (unpublished)

[18] Transport and Main Roads. 2011. Boundary Road Interchange Upgrade. Brisbane: Queensland Government.

[19] Transport and Main Roads. 2012. Bruce Highway Action Plan-Project Descriptions. Brisbane: Queensland Government. (unpublished)

[20] Viastrada. 2008. “SIDRA Solutions.” Viastrada Ltd. Accessed May 27, 2013. http://viastrada.co.nz.

[21] Transport and Main Roads. 2010. National Managed Motorways Discussion Paper. Brisbane: Queensland Government. (unpublished)

[22] Department of Infrastructure and Transport. 2013. "Intelligent Transport Systems.” Australian Government. $\begin{array}{llll}\text { Accessed } & \text { May }\end{array}$ http://www.infrastructure.gov.au.

[23] Transport and Main Roads. 2012. Bruce Widening. Brisbane: Queensland Government. (unpublished)

[24] Transport and Main Roads. 2012. Project Cost Estimating Manual. 5th ed.. Brisbane: Queensland Government.

[25] Department of Infrastructure and Transport. 2013. A Ten Year Plan for a Better, Safer Bruce Highway. Australian Government.

[26] Miller, E. M. 2005. "The Cutoff Benefit-Cost Ratio Should Exceed One.” The Engineering Economist 46 (4): 312-9.

[27] Transport and Main Roads. 2012. Capacity Projects_20120829. Brisbane: Queensland Government. (unpublished)

[28] Transport and Main Roads. 2012. Flooding Projects-20120829. Brisbane: Queensland Government. (unpublished)

Appendix A: CBA Results of BHAP.

Table A1 Results of BHAP capacity projects evaluated with CARP.

\begin{tabular}{lllrl}
\hline Project & Funding & Project name & NPV (\$) & BCR \\
\hline C1 & BHAP & Cairns SAC Stage 3-Kate St. to Aumuller St. & $-77,213,044$ & 0.03 \\
C3 & NB2 & Cairns SAC Stage 2-Robert Rd. to Foster Rd. & $45,820,000$ & 2.00 \\
C4 & BHAP & Edmonton to Gordonvale Duplication & $-156,797,288$ & 0.48 \\
C11 & BHAP & Townsville Northern Access-Intersections & $-25,251,631$ & 0.34 \\
C13 & NB2 & MacArthur \& Melton Black Drives Intersection & $24,411,154$ & 2.00 \\
C16 & BHAP & Bowen Intersection Upgrade & $-25,713,888$ & 0.04 \\
C19 & BHAP & Knobels Rd. Intersection Upgrade & $6,000,000$ & 2.20 \\
C20 & BHAP & Mackay Northern Access Upgrade-Stage 2 & $-30,352,887$ & 0.24 \\
C21 & NB2 & Mackay Northern Access Upgrade & $12,370,545$ & 1.12 \\
C23 & NB2 & Mackay Intersection Upgrades Stage 2 & $13,610,000$ & 2.40 \\
C24b & BHAP & Mackay Ring Road Stage 1 Construction & $606,633,413$ & 2.35 \\
C26 & BHAP & Hay Point Road to Mackay Duplication & $-218,508,625$ & 0.44 \\
C27 & BHAP & Hay Point Road Intersection Upgrade & $-15,145,614$ & 0.43 \\
\hline
\end{tabular}


(Table A1 continued)

\begin{tabular}{|c|c|c|c|c|}
\hline Project & Funding & Project name & NPV (\$) & BCR \\
\hline $\mathrm{C} 28$ & BHAP & Sarina to Hay Point Road Duplication & $-191,770,422$ & 0.34 \\
\hline C29 & NB2 & Sarina Northern Access Upgrade_-Coast Rd & $-4,515,257$ & 0.69 \\
\hline C30 & BHAP & Rockhampton Northern Access Upgrade—S2 & $-80,876,381$ & 0.15 \\
\hline C31 & BHAP & Rockhampton Northern Access Upgrade—S1 & $-72,730,761$ & 0.04 \\
\hline C32 & BHAP & Rockhampton Intersection upgrades & $-19,097,193$ & 0.59 \\
\hline C42 & BHAP & Tinana Interchange & $23,851,426$ & 1.48 \\
\hline $\mathrm{C} 43$ & BHAP & Wide Bay Highway Intersection (C45 built) & $-44,268,686$ & 0.11 \\
\hline $\mathrm{C} 43$ & BHAP & Wide Bay Highway Intersection (C45 not built) & $-39,240,964$ & 0.22 \\
\hline C44 & BHAP & Gympie Northern Approach Intersection Upgrades (Section D built) & $-112,261,525$ & 0.12 \\
\hline $\mathrm{C} 45 / \mathrm{C} 46$ & BHAP & Cooroy to Curra-Section D (Stages $1 \&$ 2) & $-505,185,103$ & 0.75 \\
\hline C47 & BHAP & Cooroy to Curra-Section C (Section D built) & $376,668,653$ & 1.63 \\
\hline C47 & BHAP & Cooroy to Curra-Section C (Section D not built) & $346,013,096$ & 1.58 \\
\hline C49 & NB2 & Cooroy to Curra—Section A & $-124,540,496$ & 0.84 \\
\hline C50 & BHAP & Maroochydore Road Interchange Upgrade-Stages 1 \& 2 & $-43,642,984$ & 0.79 \\
\hline C51 & BHAP & Caloundra Road to Sunshine Motorway—Stage 4 (Stages 1 4) & $-1,408,359,418$ & 0.25 \\
\hline C53 & BHAP & Boundary Road Interchange Upgrade & $-2,788,076$ & 0.97 \\
\hline C54 & NB2 & Managed Motorways_-Gateway Motorway & $370,704,869$ & 2.72 \\
\hline Total & & & $-1,765,183,215$ & 0.78 \\
\hline
\end{tabular}

Source: TMR [2].

Table A2 Results of BHAP Flood Immunity Projects evaluated with CARP.

\begin{tabular}{lllrl}
\hline Project & Funding & Project name & NPV (\$) & BCR \\
\hline F3 & BHAP & Meunga/Sunbeam/Lily & $-26,644,493$ & 0.65 \\
F4 & BHAP & Ingham to Cardwell Range Deviation & $-702,502,989$ & 0.11 \\
F4/F5 & BHAP & Cattle/Ingham/Cardwell & $-763,858,109$ & 0.18 \\
F5 & NB2 & Cattle and Frances Creek Upgrade & $-109,714,804$ & 0.21 \\
F6 & BHAP & Haughton River Upgrade & $-397,283,384$ & 0.11 \\
F8 & BHAP & Burdekin Deviation Stages 1 and 2 & $-377,662,248$ & 0.74 \\
F9 & NB2 & Yellow Gin Creek Upgrade & $-43,725,950$ & 0.09 \\
F10 & NB2 & Sandy Gully Bridge Upgrade & $-70,035,637$ & 0.07 \\
F11 & BHAP & Goorganga Plains Upgrade-Preserve & $-304,170,956$ & 0.07 \\
F12 & BHAP & Jumper Creek Upgrade & $-9,116,930$ & 0.37 \\
F13 & NB2 & Yeppen Floodplain South Upgrade & $-149,309,621$ & 0.49 \\
F14 & BHAP & Currajong Creek Bridge Upgrade & $-44,566,698$ & 0.16 \\
F15 & BHAP & Saltwater Creek Bridge Upgrade & $-38,291,244$ & 0.25 \\
F16 & BHAP & Tiaro Flood Immunity Upgrades & $240,839,436$ & 6.20 \\
\hline Total & & & $-1,983,825,834$ & 0.49 \\
\hline
\end{tabular}

Source: TMR [2].

Appendix B: Capital Cost Estimates.

Table B1 Capital costs and estimate stage (capacity projects).

\begin{tabular}{lllrl}
\hline Project & Type & Project name & Capital cost (\$) & Estimate stage \\
\hline C1 & BHAP & Cairns SAC Stage 3-Kate St. to Aumuller St. & $80,000,000$ & P90 \\
C3 & NB2 & Cairns SAC Stage 2-Robert Rd. to Foster Rd. & $58,000,000$ & P90 \\
C4 & BHAP & Edmonton to Gordonvale Duplication & $300,000,000$ & P90 \\
C11 & BHAP & Townsville Northern Access-Intersections & $30,000,000$ & Other \\
C13 & NB2 & MacArthur \& Melton Black Drives Intersection & $26,000,000$ & P50 \\
\hline
\end{tabular}


(Table B1 continued)

\begin{tabular}{lllrl}
\hline Project & Type & Project name & Capital cost (\$) & Estimate stage \\
\hline C16 & BHAP & Bowen Intersection Upgrade & $20,000,000$ & Other \\
C19 & BHAP & Knobels Rd. Intersection Upgrade & $5,000,000$ & Planning \\
C20 & BHAP & Mackay Northern Access Upgrade-Stage 2 & $40,000,000$ & Other \\
C21 & NB2 & Mackay Northern Access Upgrade & $80,000,000$ & Other \\
C23 & NB2 & Mackay Intersection Upgrades Stage 2 & $9,000,000$ & Other \\
C24b & BHAP & Mackay Ring Road Stage 1 Construction & $450,000,000$ & Planning \\
C26 & BHAP & Hay Point Road to Mackay Duplication & $390,000,000$ & Strategic \\
C27 & BHAP & Hay Point Road Intersection Upgrade & $20,000,000$ & Strategic \\
C28 & BHAP & Sarina to Hay Point Road Duplication & $290,000,000$ & Other \\
C29 & NB2 & Sarina Northern Access Upgrade-Coast Rd. & $11,000,000$ & Other \\
C30 & BHAP & Rockhampton Northern Access Upgrade-S2 & $95,000,000$ & Unit rates \\
C31 & BHAP & Rockhampton Northern Access Upgrade-S1 & $75,000,000$ & Unit rates \\
C32 & BHAP & Rockhampton Intersection Upgrades & $30,000,000$ & Strategic \\
C42 & BHAP & Tinana Interchange & $50,000,000$ & Other \\
C43 & BHAP & Wide Bay Highway Intersection (C45 built) & $50,000,000$ & Other \\
C44 & BHAP & Wide Bay Highway Intersection (C45 not built) & $110,000,000$ & Other \\
C45/C46 & BHAP & Gympie Northern Approach Intersection Upgrades (Section D built) & $2,050,000,000$ & Concept \\
C47 & BHAP & Cooroy to Curra-Section D (Stages 1 \& 2) & $600,000,000$ & Concept \\
C49 & NB2 & Cooroy to Curra-Section C (Section D built) & $790,000,000$ & Concept \\
C50 & BHAP & Cooroy to Curra-Section C (Section D not built) & $209,000,000$ & Unit rates \\
C51 & BHAP & Cooroy to Curra-Section A & $1,875,000,000$ & Prelim \\
C53 & BHAP & Maroochydore Road Interchange Upgrade-Stages 1 \& 2 & $110,000,000$ & Prelim \\
C54 & NB2 & Caloundra Road to Sunshine Motorway-Stage 4 (Stages 1 4) & $215,000,000$ & Strategic \\
\hline S0uree & TR & &
\end{tabular}

Source: TMR [27].

Table B2 Capital costs and estimate stage (Flood Immunity Projects).

\begin{tabular}{lllrl}
\hline Project & Funding & Project name & Capital cost (\$) & Estimate stage \\
\hline F3 & BHAP & Meunga/Sunbeam/Lily & $80,000,000$ & Concept \\
F4 & BHAP & Ingham to Cardwell Range Deviation & $810,000,000$ & PPR (project proposal report) \\
F4/F5 & BHAP & Cattle/Ingham/Cardwell & $145,000,000$ & PPR/concept \\
F5 & NB2 & Cattle and Frances Creek Upgrade & $955,000,000$ & Concept \\
F6 & BHAP & Haughton River Upgrade & $460,000,000$ & Tender \\
F8 & BHAP & Burdekin Deviation Stages 1 and 2 & $1,430,000,000$ & Prelim \\
F9 & NB2 & Yellow Gin Creek Upgrade & $49,000,000$ & Prelim \\
F10 & NB2 & Sandy Gully Bridge Upgrade & $80,000,000$ & P90 \\
F11 & BHAP & Goorganga Plains Upgrade-Preserve & $340,000,000$ & PPR \\
F12 & BHAP & Jumper Creek Upgrade & $15,000,000$ & Prelim \\
F13 & NB2 & Yeppen Floodplain South Upgrade & $296,000,000$ & Prelim \\
F14 & BHAP & Currajong Creek Bridge Upgrade & $55,000,000$ & P90 \\
F15 & BHAP & Saltwater Creek Bridge Upgrade & $52,000,000$ & Strategic \\
F16 & BHAP & Tiaro Flood Immunity Upgrades & $60,000,000$ & Strategic \\
\hline
\end{tabular}

Source: TMR [28]. 
Appendix C: Map of Bruce Highway.
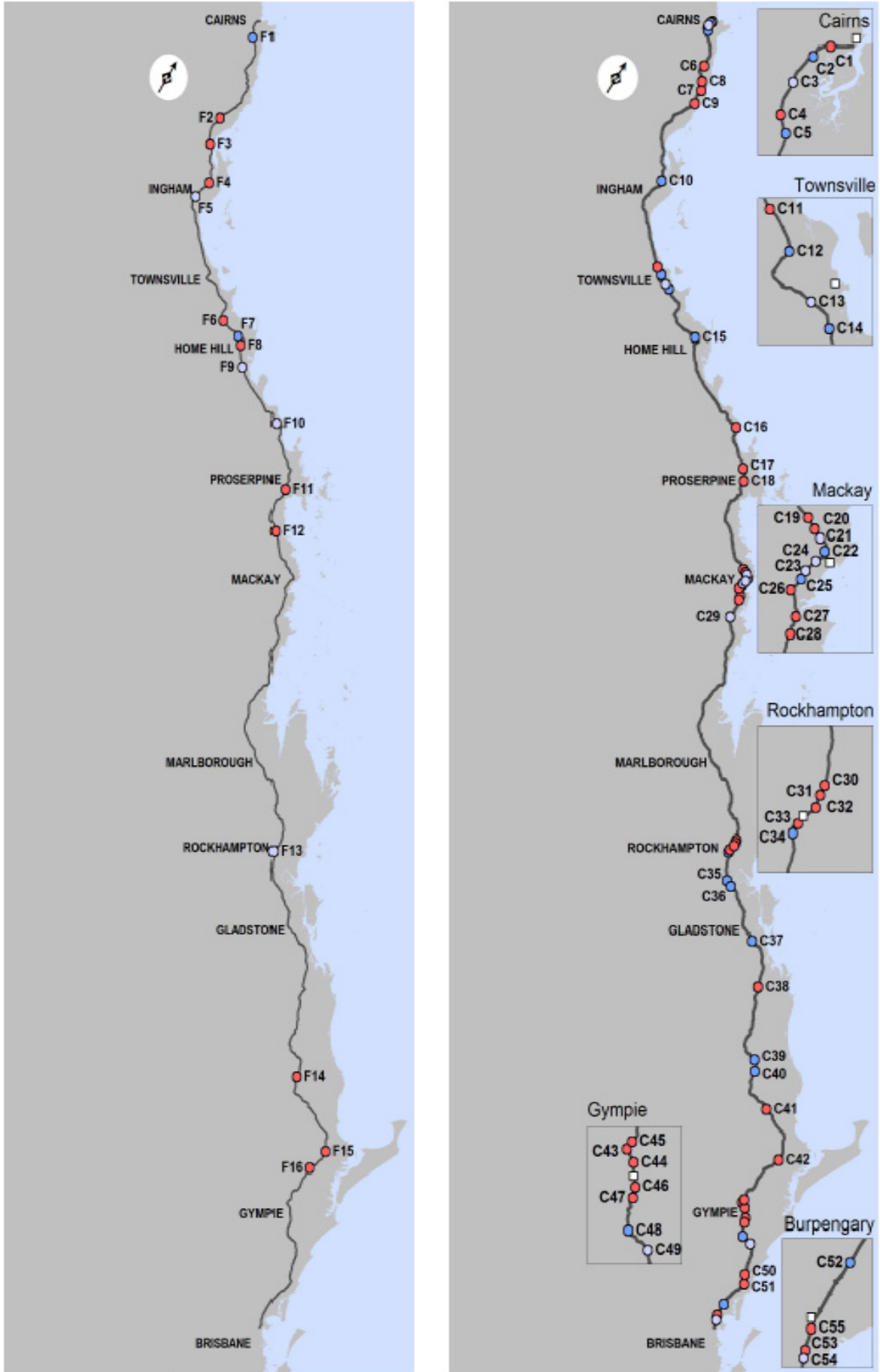

Fig. C1 Map of the Bruce Highway and proposed projects.

Source: TMR [2]. 